\title{
Trends in hysterectomy for benign causes - A retrospective study at Kohalpur Teaching Hospital
}

\author{
Renjhen P*, Behura S*, Acharya S*
}

\section{ABSTRACT}

A retrospective study of all hysterectomies was done from $1^{\text {st }}$ January 2001 to $31^{\text {st }}$ December 2001. The objective was to study the trends in age, parity, indications, type of surgery (abdominal or vaginal), conservation of ovaries, repair of pelvic floor and postoperative complications. All cases were reviewed for the above parameters.

73 hysterectomies were performed during this period, of which $57.53 \%$ were abdominal and $42.47 \%$ were vaginal.

Maximum numbers of operations (41.09\%) were in the age groups of 31 to 40 years and $41-50 \mathrm{yrs}(35.61 \%)$. Ovaries were conserved in $50 \%$ cases.

Commonest indication was utero-vaginal prolapse (46.6\%) followed by cervical intra-epithelial neoplasia (CIN) (28.77\%), leiomyomas (20.54\%) and dysfunctional uterine bleeding (DUB) (4.10\%). Pelvic floor repair accompanied almost all $(97 \%)$ vaginal hysterectomies.

Key Words: Hysterectomy, pelvic inflammatory disease, cervical intra epithelial neoplasia, utero-vaginal prolapse, DUB.

\section{INTRODUCTION}

Hysterectomy is one of the most common gynecological procedures performed .After caesarean section it is the second most frequently performed major surgery in U.S.A. ${ }^{1}$ The rate of hysterectomy has varied between 6.1 and 8.6/1000 women of all ages. About $75 \%$ of all hysterectomies are performed in women between the ages 20-49 years. The common indications for which hysterectomy is performed include leiomyoma, prolapse, endometriosis, malignancy and endometrial hyperplasia.

* Kohalpur Teaching Hospital, Nepalgunj Medial College, Banke, Nepal. Address for correspondence : $\quad$ Dr. Prachi Renjhen

282 S.D. Block, Tower Apartment

Pitampura, N Delhi 110088

Email: renjhen@yahoo.com

\section{MATERIALS AND METHODS}

A retrospective study of women who underwent hysterectomies at the Kohalpur Hospital in the year Jan 2001 to Dec 2001 was carried out. The cases were reviewed for age, parity indications, type of surgery whether abdominal or vaginal, conservation of ovaries, repair of pelvic floor and post operative complications. Later data was then analyzed to study the evolving trends. 
OBSERVATIONS \& RESULTS

Table I : Age group of patients having undergone Hysterectomy 